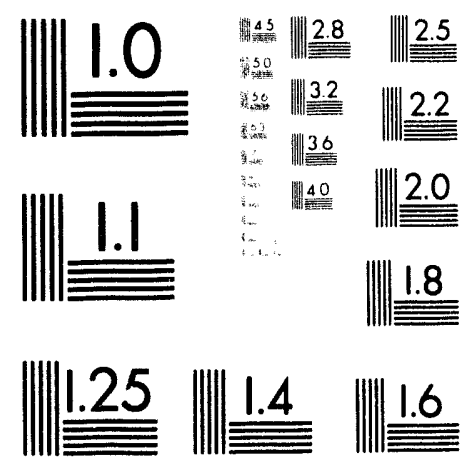



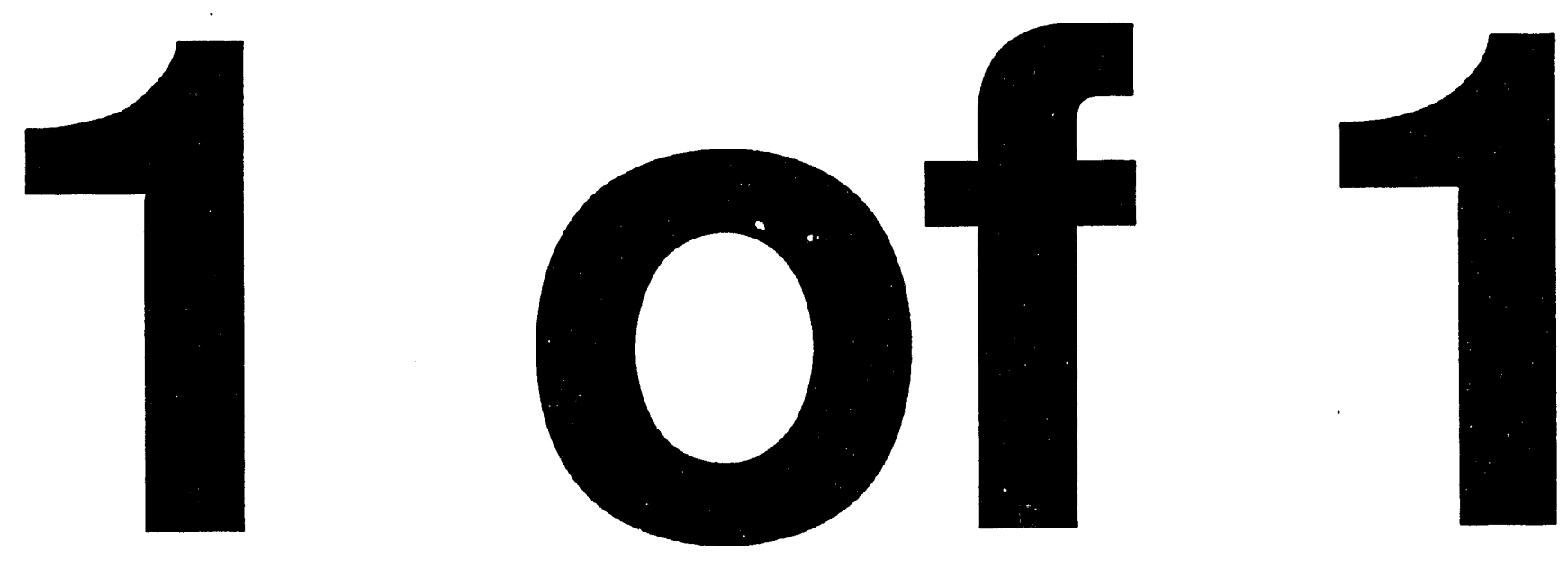


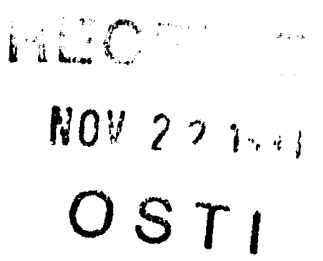

\section{ENVIRONMENT, SAFETY, AND HEALTH REgulatory IMPLEMENTATION PLAN}

\section{October 1993}

\section{DISCLAIMER}

This report was prepared as an account of work sponsored by an agency of the United States Government. Neither the United States Government nor any agency thereof, nor any of their employees, makes any warranty, express or implied, or assumes any legal liability or responsibility for the accuracy, completeness, or usefulness of any information, apparatus, product, or process disclosed, or represents that its use would not infringe privately owned rights. Reference herein to any specific commercial product, process, or service by trade name, trademark, manufacturer, or otherwise does not necessarily constitute or imply its endorsement, recommendation, or favoring by the United States Government or any agency thereof. The views and opinions of authors expressed herein do not necessarily state or reflect those of the United States Government or any agency thereof. 


\section{INTENDED FOR PUBLIC RELEASE}

This report has been reproduced from the best available copy. Available in paper copy and microfiche.

Number of pages in this report: 22

DOE and DOE contractors can obtain copies of this report from:

Office of Scientific and Technical Information

P.O. Box 62

Oak Ridge, TN 37831

(615) 576-8401

This report is publicly available from:

National Technical Information Service

Department of Commerce

5285 Port Royal Road

Springfield, VA 22161

(703) $487-4650$ 


\section{ENVIRONMENT, SAFETY, AND HEALTH REGULATORY} IMPLEMENTATION PLAN

\section{October 1993}

Prepared for U.S. Department of Energy UMTRA Project Office Albuquerque, New Mexico

Prepared by Jacobs Engineering Group Inc. Albuquerque, New Mexico 


\section{TABLE OF CONTENTS}

Section

Page

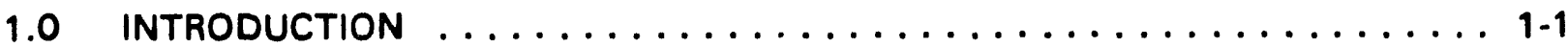

$1.1 \quad$ Background ............................

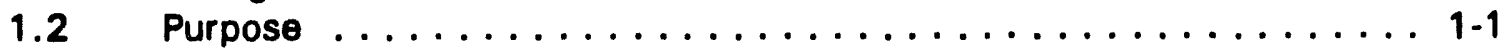

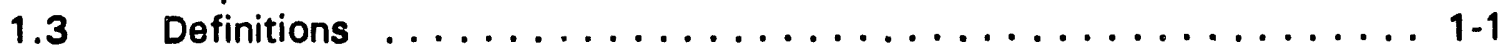

1.4 Responsibilities . . . . . . . . . . . . . . . . . . 1-3

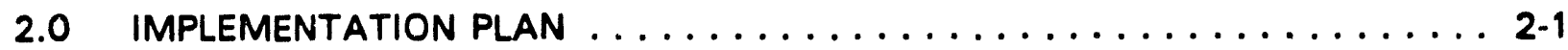

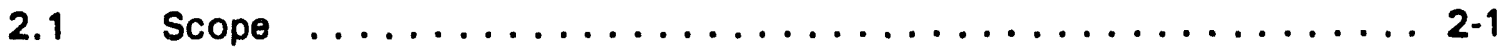

2.2 Establishing the baseline UMTRA ES\&H operating envelope . . . . . . 2-1

2.2.1 Baseline RID . . . . . . . . . . . . . . . 2-1

2.2.2 Baseline SIR .................... 2-1

2.2.3 Baseline UMTRA ES\&H operating envelope data base . . . 2-2

2.3 Completing the UMTRA ES\&H operating envelope . . . . . . . . 2-2

2.3.1 Site-specific RIDs . . . . . . . . . . . . . . . 2-2

2.3.2 Site-specific SiRs . . . . . . . . . . . . . . 2-3

2.3.3 Determining applicability of criteria statements . . . . . 2. 2-3

2.3.4 Assessing and verifying compliance status . . . . . . . 2.3

2.4 Maintaining the UMTRA ES\&H operating envelope . . . . . . . . 2.4

2.4.1 Identifying new requirements .............. 2-4

2.4.2 Determining applicability . . . . . . . . . . . . 2-4

2.4.3 Assessing and verifying compliance . . . . . . . . 2-5

2.4.4 Tracking compliance audit findings ........... 2-5

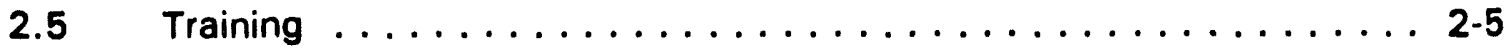

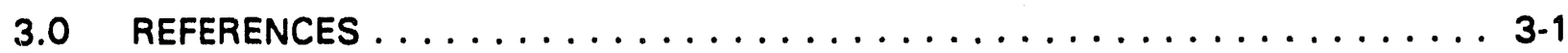

ATTACHMENT 1 FLOWCHART FOR DETERMINING APPLICABILITY 


\section{LIST OF ACRONYMS}

Acronym

ATS

DOE

ES\&H

IPC/RCS

RAC

RID

ROCS

SIR

SME

TAC

UMTRA

\section{Description}

Action Tracking System

U.S. Department of Energy

environment, safety, and health

Integrated Project Control/Regulatory Compliance System

Remedial Action Contractor

requirements identification document

Regulatory Oversight and Compliance Support

systems identification report

subject matter expert

Technical Assistance Contractor

Uranium Mill Tailings Remedial Action 


\subsection{INTRODUCTION}

\subsection{BACKGROUND}

To identify, document, and maintain the Uranium Mill Tailings Remedia' Action (UMTRA) Project's environment, safety, and health (ES\&H) regulatory requirements, the U.S. Department of Energy (DOE) UMTRA Project Office tasked the Technical Assistance Contractor (TAC) to develop a regulatory operating envelope for the UMTRA Project. The system selected for managing the UMTRA regulatory operating envelope data base is based on the Integrated Project Control/Regulatory Compliance System (IPC/RCS) developed by WASTREN, Inc. (WASTREN, 1993). The IPC/RCS is a tool used for identifying regulatory and institutional requirements and indexing them to hardware, personnel, and program systems on a project. The IPC/RCS will be customized for the UMTRA Project surface remedial action and groundwater restoration programs.

\subsection{PURPOSE}

The purpose of this plan is to establish the process for implementing and maintaining the UMTRA Project's regulatory operating envelope, which involves identifying all applicable regulatory and institutional requirements and determining compliance status. The plan describes how the Project will identify ES\&H regulatory requirements, analyze applicability to the UMTRA Project, and evaluate UMTRA Project compliance status.

\subsection{DEFINITIONS}

Applicability analysis notebook. A document containing all the regulatory criteria that are potentially applicable to a given functional area for UMTRA operations (e.g., occupational safety and health and fire protection). Upon completion of the applicability analysis process, criteria determined not applicable to the UMTRA Project will be referenced in the applicability analysis notebook(s) with Project-specific justification(s) for their nonapplicability.

Compliance assessment notebook. A document containing all the regulatory criteria determined applicable to a given functional area for UMTRA operations. Upon completion of the self-assessment process, Project implementing documents (e.g., procedures, training records, and inspection records) containing the compliance criteria will be referenced in the compliance assessment notebook(s) to validate how the Project meets the regulatory criteria.

Criterion statement. An individual mandatory prescriptive requirement that is part of an institutional, regulatory, or state requirements document (i.e., "The portable fire extinguisher shall be inspected monthly."). 
ES\&H operating envelope. All ES\&H regulatory requirements applicable to UMTRA Project operations that must be met in order to achieve an acceptable level of regulatory compliance. For the UMTRA Project, the ES\&H operating envelope will be defined by utilizing requirements identification documents (RID), systems identification report (SIR) reviews, applicability analyses, and subsequent compliance assessment.

Functional area. A grouping of criterion statements based upon activity discussed or program impact. For example, the fire protection program functional area contains all criterion statements pertaining to fire protection issues, including installation of fire sprinkler systems, inspection and maintenance of portable fire extinguishers, fire hazard surveys, etc. This functional area concept is maintained throughout the data base, including applicability analysis and compliance assessment notebooks, to optimize review of programmatic elements.

Requirements document. An institutional or regulatory document that prescribes ES\&H standards that must be evaluated to establish the ES\&H operating envelope. Examples include Federal, state, or local regulations, DOE Orders, memoranda of understanding, cooperative agreements, permits, industry standards, and guidance documents.

Requirements identification document. A document that identifies all institutional and regulatory documents with potential applicability to the UMTRA Project. This document also contains justification statements for all institutional and regulatory documents deemed "not applicable" to the Project during the review process.

Subject matter expert (SME). An individual who, due to depth of knowledge on a given issue and/or extensive technical expertise, is recognized as an expert in providing interpretational guidance regarding specific regulatory, institutional, or facility issues.

Systems identification report. A document that identifies site-specific equipment, processes, and related componentry required to support operations at the UMTRA Project. This document also describes the location and scope of activities performed at the site.

UMTRA ES\&H operating envelope data base. A computerized data base that contains records of institutional and regulatory requirements applicable to the UMTRA Project by regulatory document, subject, or system on an individual criterion basis. The data base software includes a built-in system for tracking open-compliance status or audit findings for individual regulatory criteria statements. 


\subsection{RESPONSIBILITIES}

To ensure effective implementation, documentation, and maintenance of the UMTRA ES\&H operating envelope, the Project participants' responsibilities have been delineated as follows:

Grand Junction Projects Office and RUST-Geotech. Support evaluation of criteria statements as they apply to Grand Junction, Colorado, vicinity properties, and long-term surveillance of disposal sites; provide justification for determinations and compliance documentation; and implement institutional and regulatory requirements.

TAC Regulatery Oversight and Compliance Suppert (ROCS) Department. Maintains the UMTRA ES\&H operating envelope data base; identifies new institutional and regulatory requirements; determines general applicability to the UMTRA Project; and supports the UMTRA Project Office by coordinating reviews and input from other Project participants. ROCS also generates procedures and desk instructions to control and define all aspects of the ES\&H operating envelope self-assessment process, including applicability determinations, acceptable adherence and implementing documentation, prioritization of activities, etc.

Remedial Action Centracter (RAC). Supports evaluation of criteria statements as they apply to surface remedial actions; provides justification for determinations and compliance documentation; and implements institutional and regulatory requirements.

Technical Assistance Contractor. Supports evaluation of criteria statements as they apply to surface remedial actions and groundwater restoration activities; provides justification for determinations and compliance documentation; and implements institutional and regulatory requirements.

UMTRA ES\&H Committee. Assists in the evaluation of new and revised ES\&H requirements and expedites the implementation of ES\&H requirements. The UMTRA ES\&H Committee also assists in problem resolution regarding ES\&H subjects among Project participants.

UMTRA Project Office ES\&H Manager. Reviews and approves applicability determinations and compliance documentation; distributes institutional and regulatory requirements to Project participants; requests clarifications of applicability and approvals of implementation plans from DOE Albuquerque Operations Office and DOE Headquarters as necessary; and chairs UMTRA ES\&H Committee. 


\subsection{IMPLEMENTATION PLAN}

\subsection{SCOPE}

The UMTRA ES\&H operating envelope implementation will address the following:

- Establishing a baseline regulatory operating envelope to provide consistent methods for identifying and evaluating all Project ES\&H requirements.

- Documenting applicability and compliance criteria at the regulatory requirement document level and on an individual requirement basis.

- Maintaining the regulatory operating envelope.

- Tracking open items with unresolved compliance status, (e.g., required procedure not generated yet) and tracking audit findings and corrective actions on an as needed basis.

To be effective, the UMTRA ES\&H operating envelope must be well documented and user-friendly. ROCS has primary responsibility for developing and maintaining the ES\&H operating envelope. Other Project participants may use the UMTRA ES\&H operating envelope to identify applicable regulatory and institutional requirements and will assist ROCS with compliance status determinations.

\subsection{ESTABLISHING THE BASELINE UMTRA ES\&H OPERATING ENVELOPE}

The UMTRA ES\&H operating envelope has three primary components: RIDs, SIRs, and a relational data base. All of these components were developed for the UMTRA Grand Junction, Colorado, operation to establish the baseline UMTRA ES\&H operating envelope.

\subsubsection{Baseline RID}

The requirements documents for the UMTRA Project's Grand Junction, Colorado, operations are identified and documented in the Grand Junction RID (DOE, 1992). The RID also provides justifications for requirements documents determined not applicable to the Grand Junction operation.

\subsubsection{Baseline SIR}

The site-specific equipment, processes, and related componentry required to support Grand Junction's operations are identified and documented in the Grand Junction SIR (DOE, 1992). 


\subsubsection{Baseline UMTRA ES\&H operating envelope data base}

The baseline UMTRA ES\&H operating envelope data base, which is a customized version of the WASTREN IPC/RCS, contains all the criteria statements from the requirements documents that apply to surface remedial actions in Grand Junction, Colorado, including the vicinity property program. The criteria statements are indexed to the primary functional area (e.g., fire protection), subsystem (e.g., fire protection and management), and subsubsystem (e.g., fire hazard analysis) to which they apply. The UMTRA ES\&H operating envelope data base is on the UMTRA main computer and can be accessed using the UMTRA local area network.

The existing ES\&H operating envelope data base will be expanded to include all ES\&H regulatory requirements that address both surface remedial action activities and groundwater restoration for the remaining UMTRA sites. Due to the complexity of the Grand Junction operations, most Federal regulatory requirements applicable to other sites have already been entered into the data base.

\subsection{COMPLETING THE UMTRA ES\&H OPERATING ENVELOPE}

The current ES\&H operating envelope contains all of the individual criteria statements for applicable requirements documents. Since most of these documents contain criteria statements not applicable to UMTRA, individual criteria should be evaluated for UMTRA applicability.

This evaluation process will be addressed through applicability analysis (does the criteria statement apply to UMTRA operations?) and subsequent compliance assessment (does UMTRA have sufficient Project documentation to address status of compliance with criteria which have been determined to be applicable to UMTRA operations?). The results of this evaluation process will be contained in two sets of documents, referred to as applicability analysis and compliance assessment notebooks, respectively.

Applicability analysis and compliance assessment notebooks can be developed for individual sites based upon unique activities and direction from the Project Office.

\subsubsection{Site-specific RIDs}

The Grand Junction RID will serve as the template for other UMTRA sites where surface remedial actions have not been completed or started, and for all UMTRA sites requiring groundwater restoration. These site-specific RIDs will be generated on an as-needed basis, contingent upon site schedules and directives from the UMTRA Project Office. Currently, the site-specific surface remedial action RIDs are expected to include 9 sites in five states, and the groundwater restoration RIDs will address 20 sites in nine states. 


\subsubsection{Site-specific SIRs}

The equipment, processes, and related componentry required to support operations at other UMTRA Project sites will be developed through a detailed site verification and site-specific documentation review. Guidance and planning documents, conceptual designs, and interviews with the UMTRA Project Office, TAC, and RAC SMEs will identify potential systems and equipment to be utilized at sites where surface remedial action has not yet begun and for sites anticipating groundwater restoration. Site-specific SIRs will be generated as required to support site-specific RIDs (see Section 2.2).

\subsubsection{Determining applicability of criteria statements}

ROCS SMEs will evaluate individual criteria statements for applicability, with the assistance of the ES\&H Committee and other DOE/TAC/RAC SMEs as necessary. The ROCS SMEs will provide a justification for each criterion statement determined to be not applicable. The ES\&H Committee will review these justifications of nonapplicability prior to their entry into the ES\&H operating envelope data base.

ROCS personnel will enter the applicability determinations and subsequent nonapplicable justifications into the UMTRA ES\&H operating envelope data base.

Upon completion, the applicability analysis notebooks provide a ready reference regarding Project decisions for why criterion statements of a reauirements document are not applicable to UMTRA operations.

\subsubsection{Assessing and verifying compliance status}

For criteria statements applicable to UMTRA, the SMEs will determine the appropriate level of Project documentation (e.g., procedures, ES\&H programs, inspection records, etc.) needed to address the requirements of the criterion statement, and will assess the level of compliance. This appropriate level of Project documentation will be governed by a graded approach, whereby the depth of Project documentation required is determined by potential impact on such areas as worker safety and environmental concerns. Depending on the potential impact of the criterion statement to continued safe and reliable operations, verification of an acceptable level of compliance may involve documentation review. Project/site personnel interviews, or field verification. Field verifications may be performed during operational readiness reviews/evaluations, routine ES\&H audits or site visits, or reviews specially scheduled to address critical or high hazard systems.

When Project documentation is not sufficient or adequate for the applicable criterion statement, this noncompliance will be entered into the Action Tracking System (ATS) of the ES\&H operating envelope data base as an "Open itern."

ROCS will notify the responsible organization of these open items at a frequency 
determined by the ES\&H Committee. Upon receipt of appropriate Project compliance documentation, the ATS will be updated.

ROCS personnel will enter the Project documentation into the UMTRA ES\&H operating envelope data base and the ATS.

Upon compietion, the compliance assessment notebooks provide a ready reference for compliance information (e.g.. Project documentation being utilized to meet criterion statements of a requirements document or defining Project exemptions/waivers for applicable requirements which UMTRA cannot comply with).

The ES\&H operating envelope is a dynamic component of the UMTRA Project. Programs are constantly changing as site remediation activities move from one phase to another. Regulatory requirements are always being added, modified, or deleted. As a result, the UMTRA ES\&H operating envelope must be updated routinely. The following subsections describe the activities involved in maintaining the UMTRA ES\&H operating envelope.

\subsubsection{Identifying new requirements}

ROCS will identify new institutional and regulatory requirements through routine review of sources, including the Federal Register, DOE memoranda and notices, and industry journals and periodicals (e.g.. Environment Reporter). The ES\&H Committee will provide a forum for bringing new and proposed regulatory requirements to the attention of Project management and staff. ROCS SMEs will use these sources to identify any requirement that is potentially applicable to the UMTRA Project. These reviews will also include identifying changes to existing requirements.

\subsubsection{Determining applicability}

ROCS will review a requirements document identified as potentially applicable to determine its general applicability to the UMTRA Project. For requirements documents determined applicable to the UMTRA Project, ROCS will divide the new requirements document into criteria statements and conduct an initial identification of the programs impacted. For requirements documents determined nonapplicable to the UMTRA Project, the appropriate SME will generate a decision statement.

The general applicability for existing requirements documents was determined when the baseline ES\&H operating envelope was developed. Therefore, changes to these documents will only require applicability determinations on the individual criteria statements affected by the changes. 
ROCS will enter each new or changed criterion statement into the UMTRA ES\&H operating envelope data base for tracking. Copies of each criterion statement will be sent to the appropriate SME(s) for evaluation. Decision statements for requirements documents determined nonapplicable to the UMTRA Project will be entered into a subdirectory of the ES\&H operating envelope data base to provide a focal point for regulatory interpretation.

\subsubsection{Assessing and verifying comoliance}

New and revised requirements documents will be assessed and verified in a manner similar to that described in Section 2.3.4 (see Attachment 1).

\subsubsection{Iracking compliance audit findings}

ROCS will track audit findings against ES\&H requirements on the ATS. Compliance findings from internal and external ES\&H audits will be entered into the ATS. ROCS will update the ATS when notified that corrective action was taken.

\subsection{TRAINING}

The ROCS Group will conduct training sessions to acquaint Project participants with the UMTRA ES\&H operating envelope. The training sessions will be divided into the following types:

- Assessment. This session will define the duties and responsibilities of Project personnel supporting the assessment process.

- Awareness. This session will present an overview of the ES\&H operating envelope and its role in supporting UMTRA Projects.

- Management. This session will identify ES\&H operating envelope data base features that management can utilize during day-to-day activities. 


\subsection{REFERENCES}

DOE (U.S. Department of Energy), 1992. Requirements Identification Document and Systems Identification Report for the Uranium Mill Tailings Remedial Action Project at Grand Junction, Colorado, UMTRA-DOE/AL-400729.0000, DOE UMTRA Project Office, Albuquerque, New Mexico.

WASTREN, 1993. Integrated Project Control/Regulatory Compliance System Users Manual, WASTREN, Inc., Richland, Washington. 
ATTACHMENT 1

FLOWCHART FOR DETERMINING APPLICABILITY 


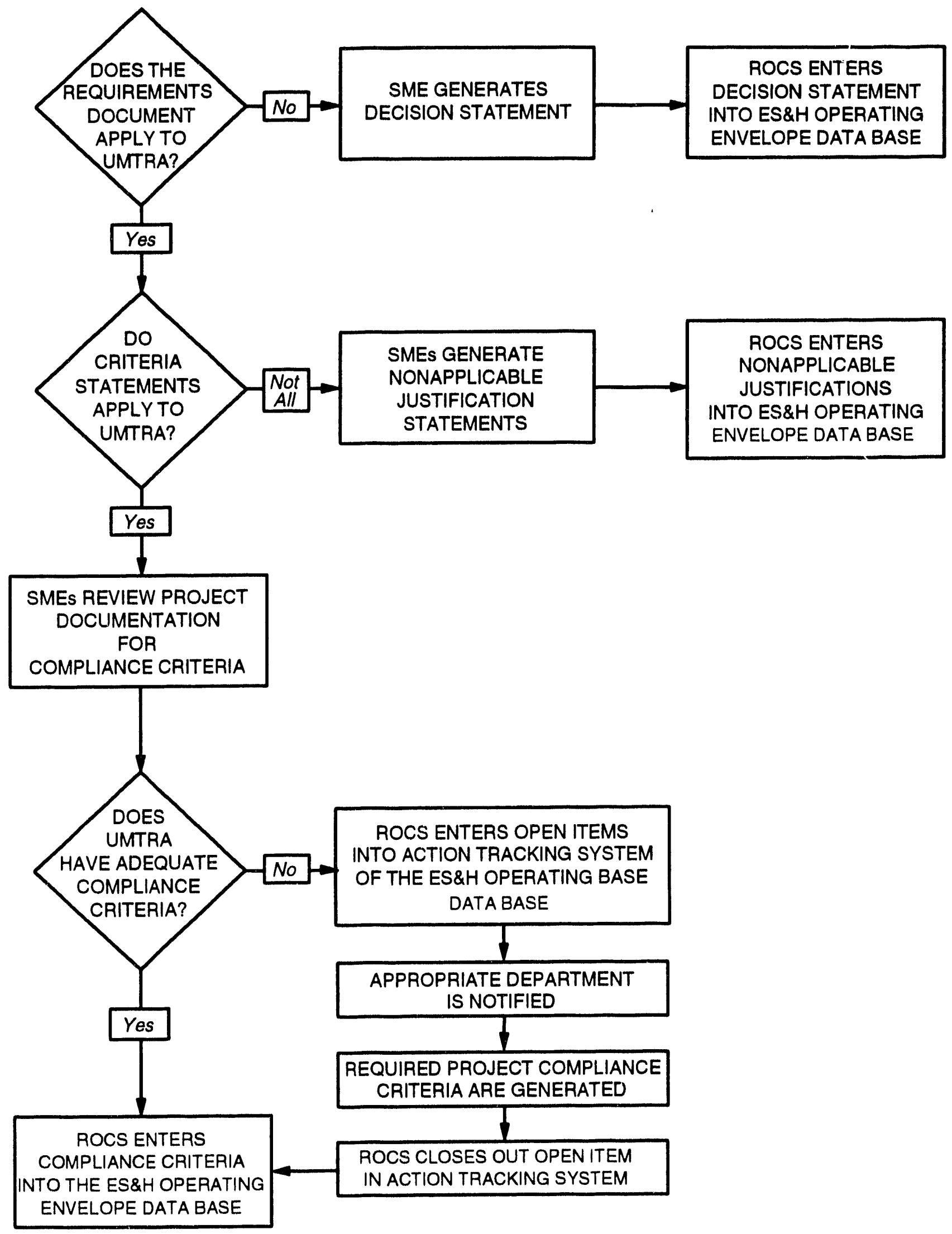

FLOWCHART FOR DETERMINING APPLICABILITY 

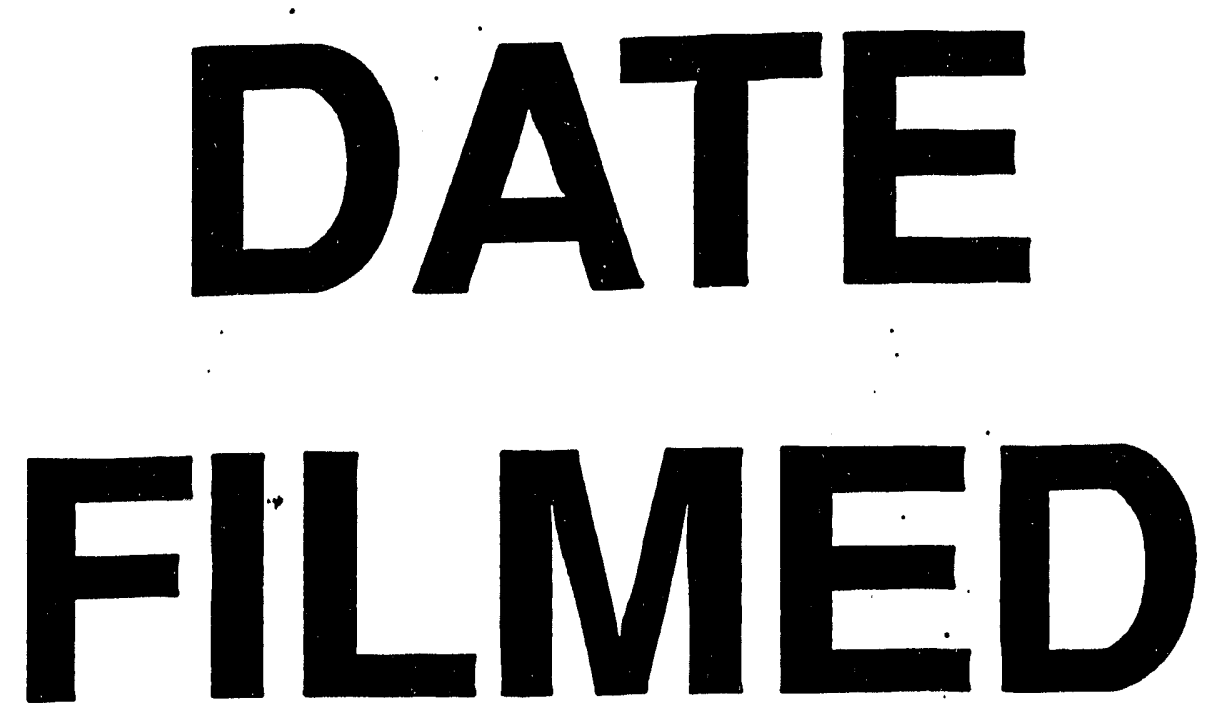

$1 / 6 / 94$
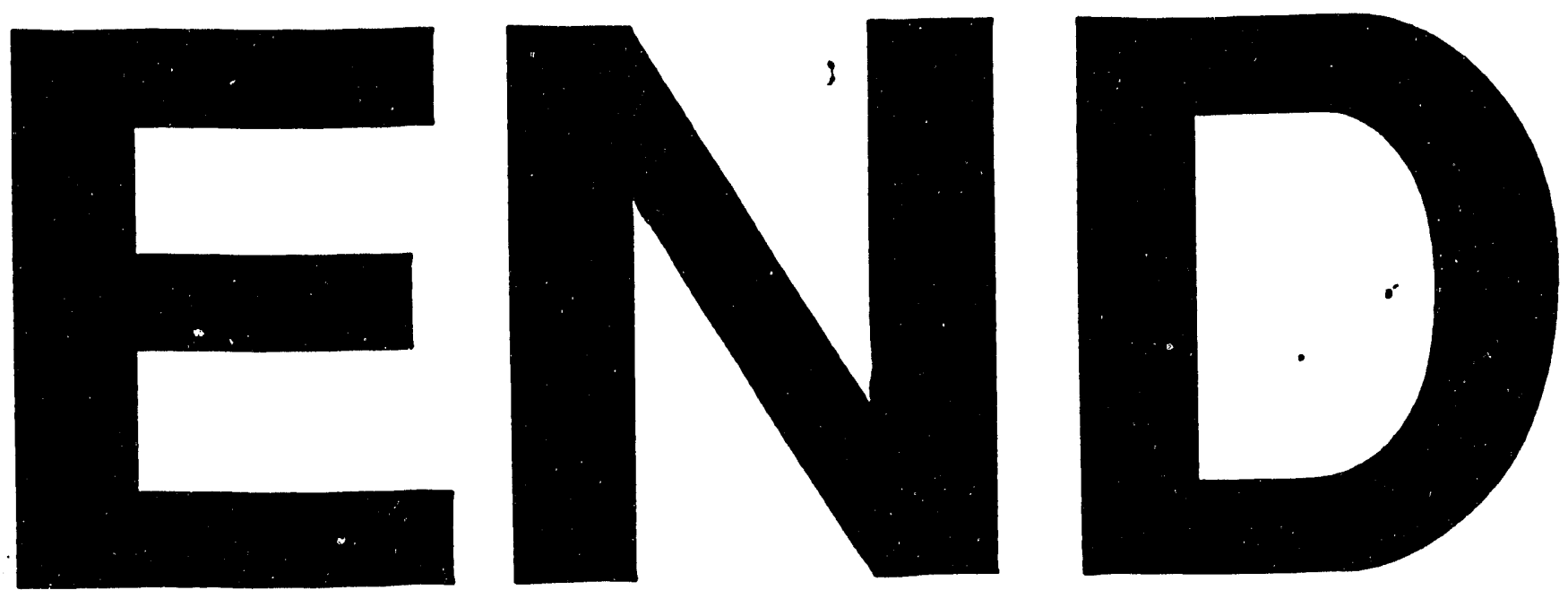
